The current issue and full text archive of this journal is available on AFEBI Management and Business Review at:

http://journal.afebi.org/index.php/ambr/article/view/403

\section{DECISION MAKING IN THE CULTURE AND CREATIVE INDUSTRIES ENVIRONMENT: LESSONS FROM THE CULTURAL VILLAGE}

\author{
Chrisna T. Permana \\ Universitas Sebelas Maret, Surakarta, Indonesia \\ Budi Harsanto* \\ Universitas Padjadjaran, Bandung, Indonesia
}

Decision Making in The Culture and Industries Environment

\begin{abstract}
Purpose - Cultural village is an area-based development concept that engages with the culture and creative industries as well as tactical urbanism. Typically, a cultural village is situated in geographical areas that have traditionally had strong cultural themes and have the potential for socio-economic growth in the surrounding region. Decision-making in this environment differs from pure-profit sector decision-making. This study set out to draw lessons from the cultural village, especially in Global South, where the culturally-led consensus approach is used to reshape group decision-making processes.
\end{abstract}

Design/methodology/approach - This study uses a systematic review method as a way to search, screen, analyze and synthesize knowledge from the academic database. The Scopus academic database is used for the search process.

Findings - This paper concludes that the inclusion of culture into decision-making offers three stages of fundamental lessons for the community, which are flexibility, openness, and innovation. These three forms the foundation for the five main elements of decision-making in the cultural village, which include inclusive, participatory, collaborative, agreement-seeking, and cooperative.

Research limitations/implications - This paper certainly has limitations, especially in terms of the number of papers reviewed. Future reviews can be carried out more broadly by expanding search keywords as well as subject areas and regions.

Originality/value - This study concludes that the implementation of culturally-based Consensus Approach (CA) in cultural villages has generally promoted inclusive, participatory, collaborative, agreement seeking, and cooperative decision-making process, although in several cases, the approach was struggled to encourage equal collaboration and effective agreement seeking.

Keywords: decision-making, cultural village, creative industry, consensus approach

Paper type Research paper

\footnotetext{
*Corresponding author. Email address: budi.harsanto@unpad.ac.id
} 
Decision-making in the profit sector has different characteristics from the nonprofit sector. For example, decision-making in the profit sector is characterized by high demands for accountability from its stakeholders (LeRoux \& Wright, 2010). A more peculiar thing happens to entities that combine profits and nonprofits, as is generally the case of cultural villages. Cultural village refers to an area-based development concept that engages with the culture and creative industries as well as tactical urbanism (Park, 2015; Talen, 2015). Cultural villages apply the specific theme of culture and creative industries as a platform and branding, which mobilize surrounding people to engage and work together for area development programs (Harsanto \& Permana, 2020; Wang, 2009).

Cultural villages usually encourage their people, centered on community leaders, activists, and academics, to be key facilitators to create more independent communities to manage local resources, address local priority issues, and organize local plans (Wagenaar \& Healey, 2015). The actions of organizing decision-making together within the community in the cultural villages, thus, have promoted an innovative consensus approach in the decisionmaking process in which we refer to as the culturally-led consensus approach (Amy, 2017; Healey, 2015). This approach emphasizes various innovations in terms of the inclusion of norms, values, social structure, and habits into decision-making procedures (Coaffee \& Healey, 2003; Fahmi et al., 2016).

The culturally-led approach is expanded from the generic Consensus Approach (CA) in decision-making (Woltjer, 2000). The CA reflects a process upon involving multiple actors and their socio-cultural backgrounds, preferences, and values into interactive processes to produce strategic decisions. The CA adds legitimacy and acceptability to the decision-making process (Woltjer, 2000). The CA comprises of five pillars: inclusive, participatory, collaborative, agreement seeking, and cooperative (Healey, 2003; Innes \& Booher, 2000; Mallett \& Cherniak, 2018; Swyngedouw, 2005; Woltjer, 2000). Inclusive indicates an open decision-making process, which is accessible for people from various backgrounds (Nakagawa, 2010). Participatory is actions that are contributed and characterized by participation, especially from multiple actors (Widianingsih \& Morrell, 2007).

The collaborative is the next stage of participatory, where such multiple actors are encouraged to share values, strategies, and commitments (Healey, 1997). Agreement seeking is a process to negotiate and accept certain 'winwin solutions' or decisions together (Innes \& Booher, 2010). Meanwhile, cooperation focuses on the social building to achieve common ends together, ensuring all parties are benefited from the decisions (Tang et al., 2018).

The purpose of this paper is to study various implementations of the culturally-led consensus approach in the cultural villages. Our intention is to highlight the overall process and its outcomes. We limit our exploration towards cultural villages in the Global South as a place where various culturally-led values, norms, and activities are still widely applied as the most important 'rules of the game' for the communities (Harsanto \& Permana, 2019; Permana \& Harsanto, 2020; Yuen, 2011). We positioned this paper as a review to help to advance the field of decision-making in the cultural village, which provides a unique context.

\section{LITERATURE STUDY}

Decision-making concern with the process of making choices from the various alternatives available, with the approach to systematically conducting analysis in decision making is known as decision theory (Render et al., 2018). In general, the steps for making a decision including defining the problem, list possible alternatives, identify possible outcomes, analysis the payoff, selection, and implementation (Render et al., 2018). The decision-making can be individual or non-individual in nature. Research on decision-making has a very long history, even since pre-history (Buchanan, 2006). Buchanan (2006), in Harvard Business Review, developed a timeline that illustrates that decision-making has a rich and long history from pre-history as a starting points to the current era in the 21 st century.

The development of decision-making studies in the 20th century was influenced, among others, from the fields of psychology and business economics. From a psychological point of view, the influential work, for example from Sigmund Freud in the 1900s who suggested that human decision-making is often based on something hidden (Buchanan, 2006). Meanwhile, in the field of business economics, several important studies, for example from Irving Fisher in the 1900s who introduced the concept of net present value, or Chester Barnard in the 1930s which distinguished between personal decision making and organizational decision making in the context of business (Buchanan, 2006). Some well-known theories or concepts in the subsequent development including game theory from Von Neumann \& Morgenstern in 1944 (Von Neumann \& Morgenstern, 2007) or bounded rationality from Herbert Simon in 1947 (Brown, 2004).

The study of decision making has not only been going on for a long time, but it also involves a wide range of disciplines, for example - to mention a few - mathematics, sociology, psychology, economics, management, political science, and others (Buchanan, 2006). Ward Edwards' classic article in Psychological Bulletin, for example, interestingly combines psychological perspectives and business economics in the development of decision-making theory (Edwards, 1954). Edwards' discusses the risk aspects as well as the use of statistics in psychological experiments in a business economics situation (Edwards, 1954). 
And the study of decision-making naturally evolves into more specific topics such as collective decisionmaking (e.g., Van Deemen \& Rusinowska, 2010), collaborative decision-making (Gillgren et al., 2019), or decision support system (e.g., Dagnino \& Viarengo, 2014; Gumbira \& Harsanto, 2019).

Much of the literature since the end of the 20th century pays particular attention to decision making in business economics, which is predominantly carried out in the context of profit, with not so many studies have been conducted in a nonprofit context. In fact, decision-making in the profit sector has different characteristics from the nonprofit sector. Among the examples of the difference is the level of accountability that is usually high in the profit sector because of the demands of various stakeholders for it, while in the nonprofit usually different (LeRoux \& Wright, 2010). Even more interesting is the decision-making in a mixed context between profit and nonprofit, for example, in a cultural village.

A cultural village is typically a village that combines culture and creative industries and represents the intersection of fields such as culture, business economics, and urban planning (Park, 2015; Talen, 2015). Cultural villages are usually located in certain geographic areas that have historically had a strong cultural theme and economically have the potential for socio-economic development in the surrounding area. Examples of cultural villages, for example, are Laweyan villages in Indonesia, Insadong in South Korea, Ærøskøbing in Denmark, or Woodstock in South Africa (Grydehøj, 2012; Harsanto \& Permana, 2020). The approach to decision-making in the cultural village is unique because it is involved both in the cultural aspect and in the business economics aspect (Howkin, 2001).

The uniqueness of this decision-making process, for example, is the involvement of facilitators such as community leaders or academics to help understand and manage their resources as well as develop plans for the development of their village (Wagenaar \& Healey, 2015). Among the prominent approaches used to understand decision-making in the village context is the culturally-lead approach, which is a development of the generic Consensus Approach (Amy, 2017; Woltjer, 2000). There are five elements in this approach, including inclusive, participation, collaborative, agreement seeking, and cooperative (Healey, 2003; Innes \& Booher, 2000; Mallett \& Cherniak, 2018; Swyngedouw, 2005; Woltjer, 2000). Inclusive and participation refer to the accessibility for a wide range of stakeholders to participate in the decision-making process (Nakagawa, 2010; Widianingsih \& Morrell, 2007). Collaborative, consensus-seeking, and cooperative work entails the effort to discuss strategies and commitments in order to make collective decisions that favor all parties concerned (Healey, 1997). Consensus requires a certain amount of effort to achieve it. Buchanan (2006) highlighted that consensus is a good thing unless it is reached too quickly.

\section{RESEARCH METHODOLOGY}

To understand the decision-making process in the cultural villages, we use a systematic review method. In this method, the searching and screening process is carried out systematically on a certain database before analyzed using a certain technique (Denyer \& Tranfield, 2009). This technique is useful for being able to synthesize knowledge from existing publications and play an important role in developing a body of knowledge and informing practice as well as policy-making (Harsanto, 2020; Tranfield et al., 2003).

Systematic reviews have the character of being replicable and transparent in the process so as to minimize the bias commonly found in traditional reviews (Denyer \& Tranfield, 2009). The systematic review approach has historically developed since the 1970s through evidence-based policy and practice (EBPP) in the discipline of medicine to develop the best evidence for providing the best care for patients (Denyer \& Tranfield, 2009). This approach later developed in various disciplines, both hard and soft science (Petticrew, 2001).

Considering that the main concept being sought is a combination of the cultural village and decision making, the keywords used in the search process are "decision AND cultural village," which covers the two concepts as a whole. The search was conducted on the academic database of Scopus in the second half of 2020. The results of the rough search resulted in 422 articles. Initial screening was carried out by involving three criteria, i.e., publication type (journal article), subject area (social science), and language (English).

The screening was focused on journal articles to obtain publications that have passed through the peer-review process. The subject area is focused on social science, considering that decision-making in the cultural village is most likely discussed in this subject area. This screening was conducted to help to obtain specific literature discussing the topic being researched. This initial screening yielded 89 articles potentially relevant for this review.

The next screening was the manual reading of the title and abstract. The results of this final screening yielded 33 articles. Lastly, the final screening was performed by re-reading again more carefully the articles, to ensure the relevance with decision making as well as cultural village and global south context. This screening resulted in 11 articles. This number is not too many, but it is reasonable for a review in a preliminary or in a highly specific field (e.g., Burke, 2010). A schematic diagram of this systematic search process is shown in Figure 1.

We used a qualitative approach to conduct the analysis, capturing the research findings from each of the publications included in this review. In carrying out the analysis, we are guided by a culturally-based consensus approach consisting of inclusive, participation, collaborative, agreement seeking, and cooperative (Healey, 2003; Innes \& Booher, 2000; Mallett \& Cherniak, 2018; Swyngedouw, 2005; Woltjer, 2000).
Decision Making in The Culture and Industries Environment

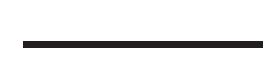


AMBR

Figure 1.

Systematic review process

Table 1.

Reviewed Articles

Technically, we read the articles included in the review manually, then create a matrix comprised of elements of the culturally-led consensus approach to capture the essence of the article findings on these five elements of the approach. In addition, we also connect the analysis with three stages of fundamental lessons for the community in their decision-making, including which are flexibility, openness, and innovation (Cars et al., 2002; Healey, 2003; Innes \& Booher, 2000; Mallett \& Cherniak, 2018; Martiskainen, 2017; Swyngedouw, 2005; Woltjer, 2000). Following that, the review findings are presented in the results and discussion section for later conclusions to be drawn.

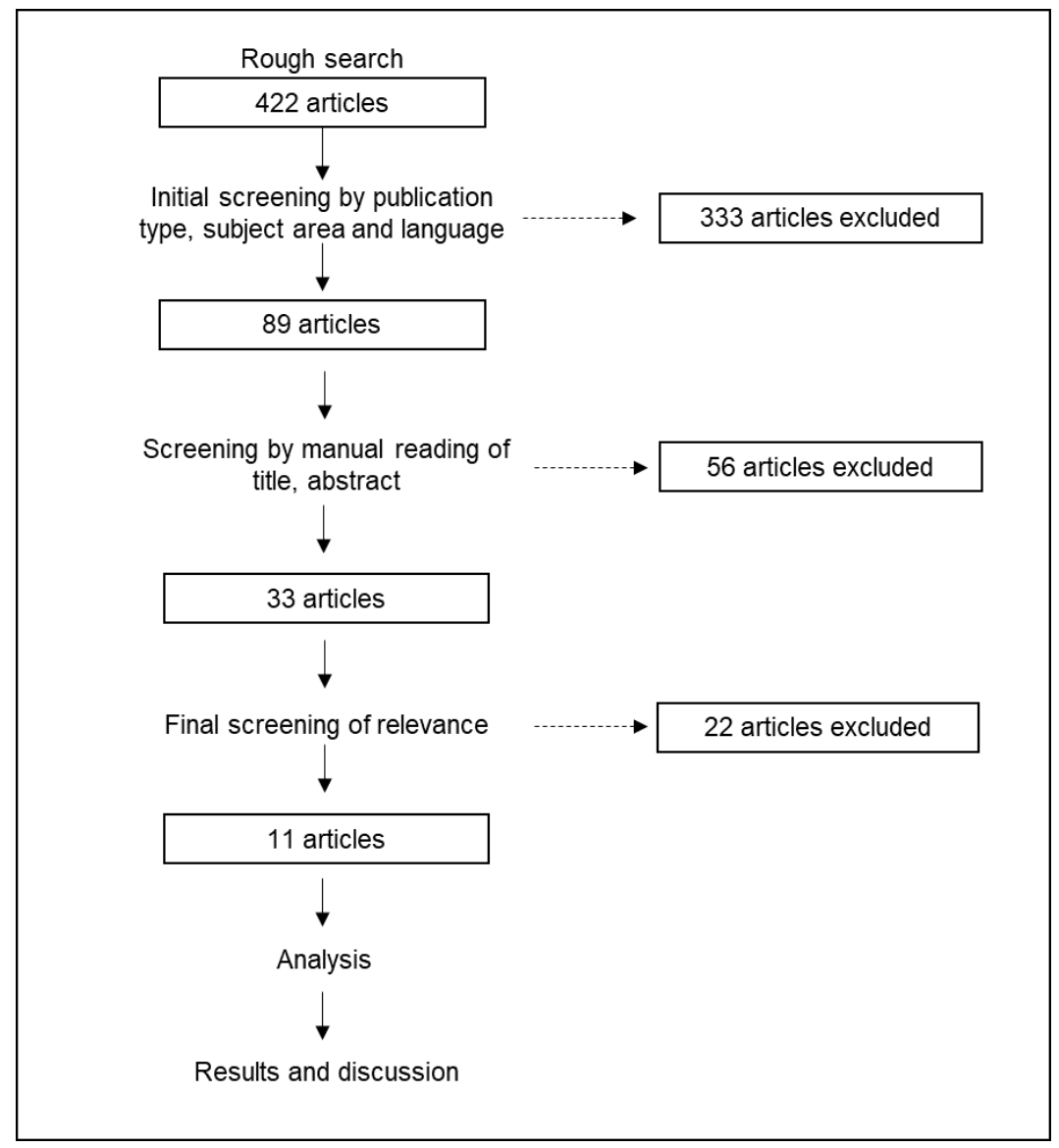

\section{RESULT AND DISCUSSION}

The profile of the articles included in this preliminary review can be seen in Table 1. We found that scholarly articles with topics related to decision-making and cultural villages are widely published in various journals from different subjects, highlighting Social Science amongst the most publishing subjects. The International Journal of the Commons, the Geography Review, and the Humanities and Social Sciences Reviews appeared as the most publishers that issued relevant articles. Since our paper was focused on the Global South context, we excluded journals from the majority of Europe and the US. Our screening process finally guided us to focus on 11 (eleven) articles mainly located in Southeast and South Asia, including Nepal, Indonesia, and China as the most appeared context.

\begin{tabular}{llll}
\hline No & Author(s) and year & \multicolumn{1}{c}{ Context } & \multicolumn{1}{c}{ Journal } \\
\hline 1. & Ching (2020) & $\begin{array}{l}\text { Mekong (Thailand, Laos, } \\
\text { Cambodia, Vietnam) }\end{array}$ & Water Alternatives \\
2. Cordero et al. (2018) & Nilgiri Hills, India & Palgrave Communications \\
3. & $\begin{array}{l}\text { Downie \& Dearden } \\
(2018)\end{array}$ & Villages in Tanzania & $\begin{array}{l}\text { South African Geographical } \\
\text { Journal }\end{array}$
\end{tabular}




\begin{tabular}{|c|c|c|c|}
\hline No & Author(s) and year & Context & Journal \\
\hline 4. & Garro (1998) & Pichataro, Mexico & Medical Anthropology Quarterly \\
\hline 5. & Ghate et al. (2013) & Eight villages in India & $\begin{array}{l}\text { International Journal of the } \\
\text { Commons }\end{array}$ \\
\hline 6. & Hasbi et al. (2019) & Toraja in Indonesia & $\begin{array}{l}\text { Humanities \& Social Sciences } \\
\text { Reviews }\end{array}$ \\
\hline 7. & $\begin{array}{l}\text { Jayasinghe \& } \\
\text { Wickramasinghe } \\
\text { (2011) }\end{array}$ & Kalametiya in Sri Lanka & $\begin{array}{l}\text { Critical Perspectives on } \\
\text { Accounting }\end{array}$ \\
\hline 8. & Justice (1983) & Villages in Nepal & Social Science and Medicine \\
\hline 9. & Khanal (2013) & Villages in Nepal & $\begin{array}{l}\text { Asia Pacific Journal of } \\
\text { Education }\end{array}$ \\
\hline 10. & $\begin{array}{l}\text { Shepherd \& Terry } \\
\text { (2004) }\end{array}$ & Bajau, Indonesia & Geography \\
\hline 11. & $\begin{array}{l}\text { Wahyuningtyas et al. } \\
\text { (2019) }\end{array}$ & Segenter in Indonesia & $\begin{array}{l}\text { GeoJournal of Tourism and } \\
\text { Geosites }\end{array}$ \\
\hline
\end{tabular}

Decision Making in The Culture and Industries Environment

Generally, the eleven articles suggest that the culturally-led Consensus Approach (CA) is preferred to be applied by cultural villages in the Global South rather than the normal consensus approach due to reasons such as to engage the community, to disperse power, and to resolve conflict. The culturally-led CA, for instance, brings more participation, allowing people from different socio-cultural backgrounds, especially those usually being excluded by the policy, to know each other, to respect differences, and seek for middle grounds (Khanal, 2013). Their continuous process to learn and work with a different socio-cultural background also gradually improves people's capacity for the provision and management of various development issues together (Khanal, 2013). In addition, culturally-led CA also builds people's enthusiasm towards decision making, brings back trust, and develops people's knowledge (Jayasinghe \& Wickramasinghe, 2011).

Generally, the eleven articles suggest that the culturally-led Consensus Approach (CA) is preferred to be applied by cultural villages in the Global South rather than the normal consensus approach due to reasons such as to engage the community, to disperse power, and to resolve conflict. The culturally-led CA, for instance, brings more participation, allowing people from different socio-cultural backgrounds, especially those usually being excluded by the policy, to know each other, to respect differences, and seek for middle grounds (Khanal, 2013). Their continuous process to learn and work with a different socio-cultural background also gradually improves people's capacity for the provision and management of various development issues together (Khanal, 2013). In addition, culturally-led CA also builds people's enthusiasm towards decision making, brings back trust, and develops people's knowledge (Jayasinghe \& Wickramasinghe, 2011).

\section{Three Lessons: Flexibility, Openness, and Innovation}

The inclusion of culture into decision-making offers three stages of fundamental lessons for the community, which are flexibility, openness, and innovation (Cars et al., 2002; Healey, 2003; Innes \& Booher, 2000; Mallett \& Cherniak, 2018; Martiskainen, 2017; Swyngedouw, 2005; Woltjer, 2000). These three principle lessons penetrate through all people's activities and their daily interactions.

Flexibility is the first crucial principle that ensures people's activities, especially in working and making decisions. It reflects the ability to follow and adapt to the social dynamics, including local priority issues as well as external trends (Holvandus \& Leetmaa, 2016). This lesson helps the community to be more capable and familiar in working with different situations and different groups of people. In the case of Peon (a traditional health practitioner) in Nepal, for instance, the culturally-led CA was applied to set local health service improvement and taught flexibility in terms of the gradual inclusion of the traditional culture of healthcare and its practitioner (the Peon) into a new and modern medical system, to succeed the introduction of the better medical standard of services for rural communities (Justice, 1983). 
The Peon was a win-win solution for the policymakers, which were expected to improve the health service quality and raise the overall wellbeing. As for the community, which seemed reluctant to accept new ideas, this decision attracted them to agree and support the new approach (Justice, 1983). Both parties agreed to negotiate and change their current ways of doing things and adapted to new approaches.

Another interesting example is in Bajau, Indonesia, where village decision-making, especially in conflict resolution, is the responsibility of the village headmen who coordinate with key authorities in decision making in the area, that is Wakatobi Marine National Park (MNP) authorities. In the case of a decline in fish stocks, flexibility is evident from this village by reacting positively to initiatives to protect these communal resources. This rarely occurs in other villages, which often show a fatalistic attitude towards communal resource degradation (R. Burke, 2001). It shows the flexibility of the Bajau institution in dealing with pressure and being able to react well to it (Shepherd \& Terry, 2004).

Openness is another important principle that ensures people's social activity within a community being accessible and free for all in the surrounding, moreover, the externals to participate. This usually occurs when communities begin to be more flexible. This lesson helps the community to be more respectful, encouraging, and shaping solidarity and a sense of belonging. In the case of disaster management in a cultural village in Indonesia, the so-called Segenter Indigenous Village community demonstrates its openness to external people as long as the external and their interactions provide advantages for the community (Wahyuningtyas et al., 2019).

Their openness, through the introduction of the culturally-led CA - through regular consensus meetings was seen from their willingness to accept NGOs from different countries and their ideas, allowing the existing people to commit to supporting new programs introduced by externals, including from different countries, such as training for building houses, bridges, and barns, workshops, and knowledge sharing on how to conserve the ecosystem, and projects on the provision of plantation equipment and mechanisms (Wahyuningtyas et al., 2019).

Innovation, on the other hand, relates to the further implications from the previous two lessons, flexibility and openness. Once communities are able to be more flexible and open, they communicate and exchange values with their externals (d'Ovidio \& Rodríguez Morató, 2017). Not only do they provide new values to their externals, the externals also promote new value to the existing communities. The more communication built, the more cooperation existed, and more learning exchanges are conducted, resulting in optimal practices and solutions for common benefits (Ghate et al., 2013). In the traditional cultural villages in India, an experiment to introduce collaborative meetings has caused many villagers to gain new skills, including communication, business, and harvesting (Ghate et al., 2013). In return, the government and related stakeholders, as the externals, have also learned some traditional values to improve their proposed system (Ghate et al., 2013).

In the following section, our paper reviews how the culturally-led Consensus Approach (CA) was implemented in the eleven cases of the cultural village. It is highlighted that the three fundamental lessons guided the decision-making process into inclusive, participatory, collaborative, agreement seeking, and cooperative - or the five pillars of a consensus approach.

\section{Decision Making in the Cultural Village Framework}

Both flexibility and openness have guided the Consensus Approach (CA) decision-making process. The commitment to include Rambu Solo - a local death ceremony - into essential public actions of the villagers in Toraja (Hasbi et al., 2019) and to accommodate rituals related to the traditional style of harvesting zone in Lombok (Wahyuningtyas et al., 2019) have successfully engaged the local people to work each other and build strong social capital amongst themselves.

On the other case, the top-down management of the Saadani Park in Tanzania has challenged public enthusiasm as many people were felt left aside and were not compromised, and thus, reduced productivity and income of the existing agricultural activities (Downie \& Dearden, 2018). However, the new approach to engage and involve the surrounding community members to share opinions, asset management, and actions together has changed enthusiasm, and in return, attracted more people to commit to supporting the development initiative (Downie \& Dearden, 2018). This situation indicates the effectiveness of culturally-led CA to promote inclusiveness which stimulates high engagement while also encouraging community members' enthusiasm.

Culturally-led Consensus Approach (CA) that were applied in the eleven cases reviewed in this paper also successfully indicated the increasing of participatory mechanisms in the various decision-making process. This is measured through the ability of the public decision-making process to invite, engage, and elaborate people from different backgrounds, highlighting the community members, the government, and think tanks (NGOs). In the case of the improvement of health services in Nepal, the Peon (traditional health practitioner) was a symbol of participatory action where the community, the health professionals, and the government worked together to negotiate disputes and to seek a more effective solution. 
It was also a commitment that members of the public were allowed to participate in the program, as the Peon and supervisors (Justice, 1983). The same situation was also reflected in the case of public participation in the schooling program in Nepal. Various decisions and executions of their programs were undertaken and supported together by all the components in the school services, including the students, parents, teachers, operators, and community organizations (Khanal, 2013). The examples indicate that the participatory aspect involves a worktogether process and negotiations from diverse stakeholders.

The collaborative process becomes important because the larger community is sometimes excluded from decision-making processes, limiting its ability to contribute. The main impediment is usually social status, which makes forming a collaborative process difficult (Ching, 2020; Hasbi et al., 2019). In fact, in a cultural village context, such as in the Nilgiri Hills in India, engage more on collective decisions than individual decisions (Cordero et al., 2018). To encourage the collaborative aspect so that it can be realized, an open environment that allows the community to respect and contribute equally need to be developed (Wahyuningtyas et al., 2019).

As for agreement seeking, gaps can occur between community members and leaders because of differences in position (Ching, 2020); in the cultural village context, social strata and cultural values dominate the decisionmaking process rather than mutual sharing (Hasbi et al., 2019). When the local community is involved and accommodated in the decision-making process, usually agreement seeking, both internally and with an outsider, will be achieved more easily. For example, in Bajau in Indonesia, the Wakatobi Marine National Park authority concluded an agreement with the community to enforce a No Fishing Zone policy around their area to protect reef fish breeding stock and has proven effective in its implementation (Shepherd \& Terry, 2004).

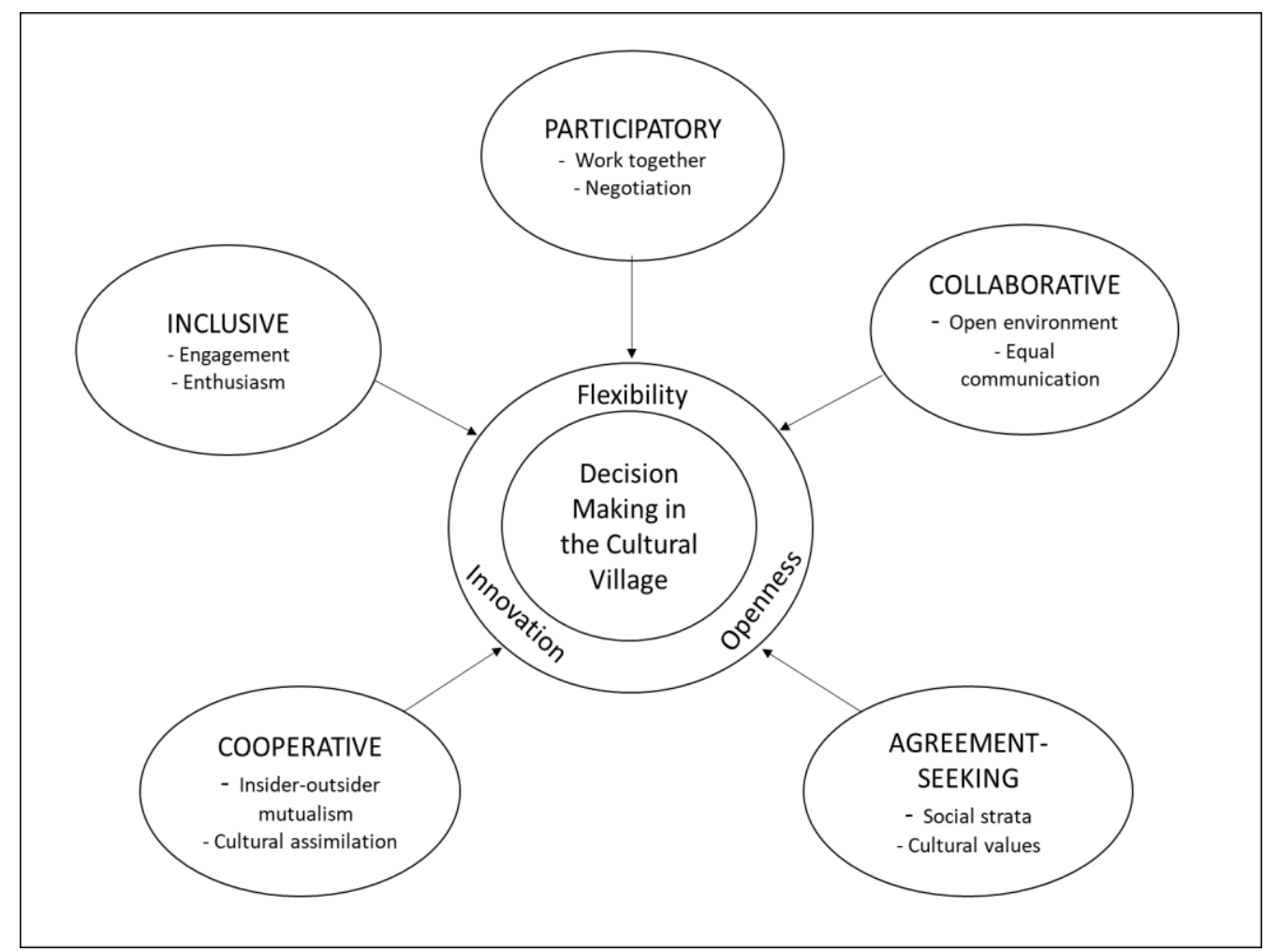

As the cooperative focuses on the social building to achieve common ends together, ensuring all parties are benefited from the decisions, our reviews of the eleven cases of culturally-led CA have shown that the majority of stakeholders were able to demonstrate cooperation. Both in the case of eight villages in India and their aims to improve productivity (Ghate et al., 2013), the disaster risk mitigation in cultural villages in Lombok (Wahyuningtyas et al., 2019), the community schooling project in Nepal (Khanal, 2013), both community, government, and NGOs were actually sharing similar values, objectives, and expectations, despite differences in their capacity, actions, and contributions.

Almost all articles also indicated that the interactions between different groups have successfully led to new skills, habits, knowledge, and strategies, all of which were the key important realization of the innovation. In the case of the Peon, for instance, a new approach in the mix of traditional and modern service was used as an effective way to improve public health services in traditional villages (Justice, 1983).
Decision Making in The Culture and Industries Environment

Figure. 2 Decision Making in the Cultural Village Framework 
There is an implication of the culturally-led Consensus Approach (CA) in decision making in the form of power imbalance. Power imbalance has caused many CA practices were ended in the domination of elites rather than a whole public power and bargaining power. This situation has made the culturally-led CA actually far from the idea of a collaborative process where multiple actors are encouraged to share values, strategies, and commitments agreement seeking where a process to negotiate and accept certain 'win-win solutions' or decisions is fully managed by equal power and mutual agreement together [16]. We highlight a case from several Srilankan villages, where the process of the engaging community into a series of decision making without strong facilitation from the government or community organization as mediators would only cause decision making ends up in a few community leaders, government elites, and those with direct access to policymakers (Jayasinghe \& Wickramasinghe, 2011). In the case of community schooling in Nepal, this situation was also reflected from their participatory meetings where many decisions were actually set and agreed upon by a few parents and school operators who have access to local leaders and politicians (Khanal, 2013).

\section{CONCLUSION}

The present study was aimed to explore the various implementation of the culturally-led consensus approach in the cultural villages. This study concludes that the implementation of culturally-based CA in cultural villages has generally promoted inclusive, participatory, collaborative, agreement seeking, and cooperative decisionmaking process, although in several cases, the approach was struggled to encourage equal collaboration and effective agreement seeking.

Findings from this paper indicate the culturally-led CA as a potential tool for policymakers to work with the community, especially to organize more bottom-up decision-making processes in traditional conservative environments. These findings suggest that flexibility, openness, and innovation helped penetrate various village member interactions in their activities. This study strengthens the relevance of the culturally-led consensus approach in decision-making in the cultural village context. Although this study focuses on the cultural village context, the findings may well have relevance to the other type of villages.

This study contributes to the understanding of decision-making in a specific context of a cultural village. By analyzing peer-reviewed publications from various geographical regions in the Global South, this study has extended our knowledge about the framework of decision-making in the cultural village. As the results of this study may be relevant for other village types besides cultural villages, the results of this study may also be useful in understanding cultural villages in a non-global South context.

As a review, this paper certainly has limitations, especially in terms of the number of papers reviewed. Future reviews can be carried out more broadly by expanding search keywords as well as subject areas and regions. In analysis, the future review can also involve a different point of view than the consensus approach (CA) as the underlying perspective. Further empirical work needs to be carried out to validate the framework developed in this study which will be a useful way in providing practical implications as well as informing policymaking in the context of cultural villages.

\section{Reference}

Amy, S. K. E. (2017). The Art of Participation: The Case of Creative Communities in Indonesia. Community Development Journal, 52(1), 171-185.

Brown, R. (2004). Consideration of the origin of Herbert Simon's theory of “satisficing”(1933-1947). Management Decision.

Buchanan, L. (2006). A Brief History of Decision Making. In Harvard Business Review. http://www.samuellearning.org/decisionmaking/handout1.pdf\%0Ahttps://hbr.org/2006/01/a-brief-historyof-decision-making

Burke, C. A. (2010). Mindfulness-based approaches with children and adolescents: A preliminary review of current research in an emergent field. Journal of Child and Family Studies, 19(2), 133-144. https://doi.org/10.1007/s10826-009-9282-x

Burke, R. (2001). Pulse of the planet: leadership models in the gloval village. Foresight.

Cars, G., Healey, P., Madanipour, A., \& De Magalhaes, C. (2002). Urban Governance, Institutional Capacity and Social Milieux. Routledge.

Ching, L. (2020). Social networks and perceptions of power in the Mekong. Water Alternatives, 13(2), $393-417$. 
Coaffee, J., \& Healey, P. (2003). "My voice: My place": Tracking transformations in urban governance. Urban Studies, 40(10), 1979-1999.

Cordero, R. L., Suma, M., Krishnan, S., Bauch, C. T., \& Anand, M. (2018). Elements of indigenous socioecological knowledge show resilience despite ecosystem changes in the forest-grassland mosaics of the Nilgiri Hills, India. Palgrave Communications, 4(1), 1-9. https://doi.org/10.1057/s41599-018-0157-x

d'Ovidio, M., \& Rodríguez Morató, A. (2017). Introduction to SI: Against the creative city: Activism in the creative city: When cultural workers fight against creative city policy. City, Culture and Society, 8, 3-6. https://doi.org/10.1016/j.ccs.2017.01.001

Dagnino, A., \& Viarengo, A. (2014). Development of a decision support system to manage contamination in marine ecosystems. Science of the Total Environment, 466-467, 119-126. https://doi.org/10.1016/j.scitotenv.2013.06.084

Denyer, D., \& Tranfield, D. (2009). Producing a Systematic Review. In The SAGE Handbook of Organizational Research Methods (pp. 671-689).

Downie, B. K., \& Dearden, P. (2018). Short-term needs trump conservation in household livelihood decisionmaking around Saadani National Park, Tanzania. South African Geographical Journal, 100(2), 196-209. https://doi.org/10.1080/03736245.2017.1342210

Edwards, W. (1954). The theory of decision making. Psychological Bulletin, 51(4), 380-417. https://doi.org/10.1037/h0053870

Fahmi, F. Z., Prawira, M. I., Hudalah, D., \& Firman, T. (2016). Leadership and Collaborative Planning: The case of Surakarta, Indonesia. Planning Theory, 15(3), 294-315. https://doi.org/10.1177/1473095215584655

Garro, L. C. (1998). On the Rationality of Decision-Making Studies: Part 1: Decision Models of Treatment Choice. Medical Anthropology Quarterly, 12(3), 319-340. https://doi.org/10.1525/maq.1998.12.3.319

Ghate, R., Ghate, S., \& Ostrom, E. (2013). Cultural norms, cooperation, and communication: Taking experiments to the field in indigenous communities. International Journal of the Commons, 7(2), 498-520. https://doi.org/10.18352/ijc.376

Gillgren, C., Støttrup, J. G., Schumacher, J., \& Dinesen, G. E. (2019). Working together: collaborative decision making for sustainable Integrated Coastal Management (ICM). Journal of Coastal Conservation, 23(5), 959-968. https://doi.org/10.1007/s11852-018-0631-z

Grydehøj, A. (2012). Negotiating heritage and tradition: identity and cultural tourism in Ærø, Denmark. Journal of Heritage Tourism, 7(2), 113-126.

Gumbira, G., \& Harsanto, B. (2019). Decision Support System for An Eco-Friendly Integrated Coastal Zone Management ( ICZM ) in Indonesia. International Journal on Advanced Science Engineering Information Technology, 9(4), 1177-1182.

Harsanto, B. (2020). Eco-Innovation Research in Indonesia: A Systematic Review and Future Directions. Journal of STI Policy and Management, 5(2), 179-191.

Harsanto, B., \& Permana, C. T. (2019). Understanding Sustainability-oriented Innovation (SOI ) Using Network Perspective in Asia Pacific and ASEAN : A Systematic Review. Journal of Asean Studies, 7(1), 1-17.

Harsanto, B., \& Permana, C. T. (2020). Sustainability-oriented innovation ( SOI ) in the cultural village : an actor-network perspective in the case of Laweyan Batik Village. Journal of Cultural Heritage Management and Sustainable Development. https://doi.org/10.1108/JCHMSD-08-2019-0102

Hasbi, Sukimi, M. F., Latief, M. I., \& Yusriadi, Y. (2019). Compromise in traditional ceremonies: A case study of the Rambu solo' ceremony in Toraja regency. Humanities and Social Sciences Reviews, 7(6), $286-291$. https://doi.org/10.18510/hssr.2019.7651

Healey, P. (1997). Collaborative Planning: Shaping Places in Fragmented Societies. Macmillan Press Ltd.
Decision Making in The Culture and Industries Environment 
Healey, P. (2015). Civil Society Enterprise and Local Development. Planning Theory and Practice, 16(1), 1127. https://doi.org/10.1080/14649357.2014.995212

Holvandus, J., \& Leetmaa, K. (2016). The Views of Neighbourhood Associations on Collaborative Urban Governance in Tallinn, Estonia. PlaNext - Next Generation Planning, 3, 49-66. https://doi.org/10.24306/plnxt.2016.03.004

Howkin, J. (2001). The Creative Economy: How People Make Money fro Idea. Penguin Group.

Innes, J. E., \& Booher, D. E. (2000). Indicators for Sustainable Communities: A Strategy Building on Complexity Theory and Distributed Intelligence. Planning Theory and Practice, 1(2), 173-186. https://doi.org/10.1080/14649350020008378

Innes, J. E., \& Booher, D. E. (2010). Planning with Complexity: An Introduction to Collaborative Rationality for Public Policy. Routledge. https://doi.org/10.4324/9780203864302

Jayasinghe, K., \& Wickramasinghe, D. (2011). Power over empowerment: Encountering development accounting in a Sri Lankan fishing village. Critical Perspectives on Accounting, 22(4), 396-414. https://doi.org/10.1016/j.cpa.2010.12.008

Justice, J. (1983). The invisible worker: The role of the peon in Nepal's health service. Social Science and Medicine, 17(14), 967-970. https://doi.org/10.1016/0277-9536(83)90223-X

Khanal, P. (2013). Community participation in schooling in Nepal: A disjunction between policy intention and policy implementation? Asia Pacific Journal of Education, 33(3), 235-248. https://doi.org/10.1080/02188791.2012.756390

LeRoux, K., \& Wright, N. S. (2010). Does performance measurement improve strategic decision making? Findings from a national survey of nonprofit social service agencies. Nonprofit and Voluntary Sector Quarterly, 39(4), 571-587. https://doi.org/10.1177/0899764009359942

Mallett, A., \& Cherniak, D. (2018). Views from above: policy entrepreneurship and climate policy change on electricity in the Canadian Arctic. Regional Environmental Change, 18(5), 1323-1336. https://doi.org/10.1007/s10113-018-1317-7

Martiskainen, M. (2017). The role of community leadership in the development of grassroots innovations. Environmental Innovation and Societal Transitions, 22, 78-89. https://doi.org/10.1016/j.eist.2016.05.002

Nakagawa, S. (2010). Socially Inclusive Cultural Policy and Arts-based Urban Community Regeneration. Cities, 27(SUPPL. 1), S16-S24. https://doi.org/10.1016/j.cities.2010.03.003

Park, S. H. (2015). Can We Implant an Artist Community? A Reflection on Government-led Cultural Districts in Korea. Cities, 56, 172-179. https://doi.org/10.1016/j.cities.2015.09.001

Permana, C. T., \& Harsanto, B. (2020). Sustainable City Planning Concepts and Practices in Emerging Economies : A Systematic Review. The Journal of Indonesia Sustainable Development Planning, I(1), 6782.

Petticrew, M. (2001). Systematic reviews from astronomy to zoology: myths and misconceptions. BMJ (Clinical Research Ed.), 322(7278), 98-101. http://www.ncbi.nlm.nih.gov/pubmed/11154628

Render, B., Ralph M. Stair, J., Hanna, M. E., \& Hale, T. S. (2018). Quantitative Analysis for Management (13th ed.). Pearson. https://doi.org/10.2307/1248691

Shepherd, S., \& Terry, A. (2004). The role of indigenous communities in natural resource management: The Bajau of the Tukangbesi Archipelago, Indonesia. Geography, 89(3), 204-213. https://doi.org/10.1080/00167487.2004.12094098

Swyngedouw, E. (2005). Governance innovation and the citizen: The Janus face of governance-beyond-the-state. Urban Studies, 42(11), 1991-2006. https://doi.org/10.1080/00420980500279869 
Talen, E. (2015). Do-it-yourself urbanism: A history. Journal of Planning History, 14(2), 135-148. https://doi.org/10.1177/1538513214549325

Tang, J. W., Chen, M. L., \& Chiu, T. H. (2018). An exploratory study on local brand value development for Outlying Island Agriculture: Local food system and actor-network theory perspectives. Sustainability (Switzerland), 10(11). https://doi.org/10.3390/su10114186

Tranfield, D., Denyer, D., \& Smart, P. (2003). Towards a methodology for developing evidence-informed management knowledge by means of systematic review. British Journal of Management, 14, 207-222. https://doi.org/10.1111/1467-8551.00375

Van Deemen, A., \& Rusinowska, A. (2010). Collective Decision Making: Views from Social Choice and Game Theory (Theory and Decision Library C).

Von Neumann, J., \& Morgenstern, O. (2007). Theory of games and economic behavior (commemorative edition). Princeton university press.

Wagenaar, H., \& Healey, P. (2015). The Transformative Potential of Civic Enterprise. Planning Theory and Practice, 16(4), 557-585.

Wahyuningtyas, N., Tanjung, A., Idris, I., \& Dewi, K. (2019). Disaster mitigation on cultural tourism in lombok, Indonesia. Geojournal of Tourism and Geosites, 27(4), 1227-1235. https://doi.org/10.30892/gtg.27409428

Wang, J. (2009). “Art in capital”: Shaping Distinctiveness in a Culture-led Urban Regeneration Project in Red Town, Shanghai. Cities, 26(6), 318-330. https://doi.org/10.1016/j.cities.2009.08.002

Widianingsih, I., \& Morrell, E. (2007). Participatory Planning in Indonesia. Policy Studies, 28(1), 1-15. https://doi.org/10.1080/01442870601121320

Woltjer, J. (2000). Consensus Planning: The Relevance of Communicative Planning Theory in Dutch Infrastructure Development. Routledge.

Yuen, B. (2011). Urban Planning in Southeast Asia: Perspective from Singapore. Town Planning Review, 82(2), $146-167$.
Decision Making in

The Culture and

Industries

Environment 